\title{
El estatus de la capital: descentralización, reforma del Estado y federalismo
}

\author{
ALICIA ZICCARDI*
}

Resumen: La ciudad de México es una de las metrópolis más grandes del mundo, una compleja realidad metropolitana y el territorio donde se localizan los poderes de la federación. El principal interrogante de este trabajo es ¿cuál es el estatus que se ha otorgado a la capital del pais en el interior de los diferentes proyectos gubernamentales de descentralización, reforma del Eslado y nuevo "federalismo", que se formularon y/o ejecutaron en México, en la última década? Las nociones de descentralización y desconcentración nos permiten evaluar los alcances de esos proyectos y el tema del federalismo mexicano se incompora en este articulo a la perspectiva en los esludios urbanos-regionales. De esta forma se les da continuidad y a la vez se enriquecen los estudios que sobre la descentralización, el forlalecimiento municipal y la reforma del Estado se han realizado en México.

\begin{abstract}
Mexico Cily is one of the largest metropolises in the world, a complex metropolitan reality, and the seat of the branches of the federation. The main aim of this article is to discover the status given to the country's capital within the various government projects concerning decentralization, state reform and the new federalism, formulated and/or implemented in Mexico during the last decade. The notions of decentralization and deconcentration enable one to evaluate the scope of these projects, while the subject of Mexican federalism is incorporated into this article from the perspective of urban-regional studies. This lends continuity to, while at the same time expanding, the studies on decentralization, the strengthening of the municipalities and State reform which have been underlaken in Mexico.
\end{abstract}

\section{INTRODUCCIÓN}

$L$

A CIUDAD DE MÉXICO es una de las metrópolis más grandes del mundo; una compleja realidad metropolitana, de alrededor de 15 millones de habitantes, cuya ciudad central es el Distrito Federal, la capital del país, territorio donde se localizan los poderes de la federación. ${ }^{1}$ Su forma de gobierno, prácticamente la misma que fue creada en 1928, se halla bajo el control del presidente de la república, quien delega su autoridad en la figura de un regente (por él designado), quien está al frente de un aparato administrativo: el Departamento del Distrito Federal. ${ }^{2}$ Este mecanismo de designación de autoridades en la capital lo

* Dirigir correspondencia al Instituto de Investigaciones Sociales, Torre II de Humanidades, $7^{\underline{a}}$ piso, Ciudad Universitaria, 04510, México, D.F.

${ }^{1}$ Según el Censo de 1990, en las 16 delegaciones del D.F. vivían 8235685 habitantes y en los 27 municipios conurbados del Estado de México un total de 6811941 habitantes. Cf. INEGI (1993). Las principales características que presenta la metrópoli son la marcada desigualdad social y la segregación urbana.

${ }^{2}$ Sobre la desaparición de los municipios de la ciudad de México y la creación del Departamento Central y las Delegaciones, véase entre otros: De Gortari, Hira y Regina Hernández (1988); González Oropeza, Manuel (1995); Cruz Rodríguez, Ma. Soledad (1994); Ziccardi, Alicia (1993); Perló, Manuel (1981). 
ejerce también el regente, quien nombra a un funcionario como autoridad máxima en cada una de las delegaciones en que se divide el territorio del D.F. En la actualidad, ya se ha iniciado un proceso de reforma al gobierno de la capital, pero por ahora (1996), la ciudadanía sólo participa en la elección de los representantes de partidos políticos para la constitución de la Asamblea Legislativa del Distrito Federal y de los consejeros ciudadanos delegacionales.

Ésta es la forma de gobierno que existe en este pequeño territorio en el que se localiza buena parte de la industria manufacturera y de los servicios del sector (comercio, informática, finanzas), se concentran los mejores equipamientos (de salud, educación y cultura), una elevada proporción de la inversión y el gasto público, y también se generan importantes recursos de la nación.

A partir de esta breve descripción, el principal interrogante de este trabajo es ¿cuál es el estatus que se ha otorgado a la capital del país en el interior de los diferentes proyectos gubernamentales de descentralización, reforma del Estado y "nuevo federalismo", que se formularon y/o ejecutaron en México, en la última década?

Comenzaremos por distinguir las nociones de descentralización y desconcentración, ejercicio útil para evaluar los alcances de esos proyectos. En este sentido, debe señalarse que entre los estudiosos de la problemática urbano-regional ha existido una gran preocupación y un interesante debate sobre esta cuestión; sobre todo, cuando la descentralización se asoció a los procesos de democratización política que se protagonizaron desde los años ochenta en diferentes países de América Latina. ${ }^{3}$

El federalismo mexicano, en cambio, ha sido materia de estudio sistemático y profundo de juristas e historiadores. ${ }^{4}$ La centralidad que ha adquirido recientemente en el interior del debate político nacional nos obliga a considerar la importancia que posee la dimensión territorial dentro del mismo. Por ello, su inclusión en los estudios urbano-regionales se torna hoy ineludible, permite dar continuidad y enriquece los estudios que sobre la descentralización, el fortalecimiento municipal y la reforma del Estado se han realizado en México.

$\mathrm{Al}$ mismo tiempo, este artículo parte de una doble constatación: $a$ ) la excesiva concentración territorial de población y actividades en el territorio de la ciudad de México; interesa considerar aquí exclusivamente el territorio del Distrito Federal, en tanto capital de la nación y sede de los poderes federales, aunque el mis-

\footnotetext{
${ }^{3}$ Un interesante debate se desarrolló a partir de un artículo de Jordi Borja (1984), publicado en la Revista Mexicana de Sociología bajo el título "La descentralización: una cuestión de método", en el cual este autor afirmaba que la descentralización era consustancial a la democracia. Véase De Mattos, Carlos (1989); Coraggio, José Luis (1989 y 1991); varios artículos contenidos en Borja, Jordi et al. (1989); Ziccardi, Alicia (1990). Un balance sobre América Latina puede hallarse en Rufián, Dolores y Eduardo Palma (1993). En México, entre otros véase Moreno Toscano, Alejandra (1982); Jacobs, Michael y Alicia Ziccardi (1984); Perló, Manuel y Alicia Ziccardi (1989); Massolo, Alejandra (1991); Martínez Assad, Carlos y Alicia Ziccardi (1992); Aguilar Barajas, Ismael (1992); Aguilar, Adrián y Boris Graizbord (1992).

${ }^{4}$ Sobre el federalismo mexicano véase: Carpizo, Jorge (1973); Sales, Carlos (1987); Ortega Lomelín, Roberto (1988); Vázquez, Josefina Zoraida (1993); Hernández Chávez, Alicia (1993); Carmagnani, Marcello (1993); González Oropeza, Manuel (1995); Lujambio, Alonso (1995), Ocaña, Lucila (1996).
} 
mo es parte de una compleja realidad metropolitana que se extiende territorialmente sobre los municipios conurbados del Estado de México; y $b$ ) la excesiva concentración de recursos, principalmente financieros y de poder político, en manos del gobierno federal. ${ }^{5}$ Ambas cuestiones son diferentes y analíticamente distinguibles, se refuerzan entre sí y están presentes en la inocultable adversidad que existe de parte de la provincia hacia el centro (la ciudad de México y el gobierno federal localizado en su territorio).

\section{LA DESCONCENTRACIÓN TERRITORIAL Y LAS PROPUESTAS DESGENTRALIZADORAS}

Desde la perspectiva del ánalisis territorial, la noción o concepto de descentralización ha dado origen a un intenso debate. En un trabajo realizado a finales de los ochenta, afirmábamos que era muy difícil

encontrarse con algún gobierno, partido político, agencia internacional u organización científico-social que no estuviera de acuerdo con la descentralización. Reagan en Estados Unidos, Pinochet en Chile, Marcos en Filipinas, Thatcher en Inglaterra, pero también los socialistas franceses, los impulsores del proceso autonómico español, los laboristas británicos, así como científicos sociales y economistas como Milton Friedman y Abby Hoffman, el Banco Mundial, y en México, el gobierno de Miguel de la Madrid, enarbolaban programas descentralizadores (Perló, Manuel y Alicia Ziccardi, 1989).

Por esta razón nos propusimos rastrear los orígenes teóricos de este binomio centralización-descentralización y coincidimos con Rondinelli (1981), quien afirmaba que

la descentralización era la transferencia o delegación de autoridad legal y política para planear, tomar decisiones y administrar funciones públicas de agencias centrales del gobierno a organizaciones de base, unidades subalternas de gobierno, corporaciones descentralizadas, autoridades regionales, funcionales, gobiernos autónomos y locales y organizaciones no gubernamentales.

El problema de fondo en los procesos de descentralización es entonces la cuota de poder que se transfiere, así como el carácter del otorgador y del receptor. Y la noción de "descentralización" se distingue de la de "desconcentración", porque esta última sólo hace referencia a los cambios que se producen en la autoridad administrativa de la línea central a niveles más bajos, y puede restringirse solamente a la "desconcentración geográfica de oficinas centrales hacia áreas dispersas, pero íntimamente relacionadas o dependientes del centro en diferentes órdenes (administrativo, financiero, etcétera)" (idem.).

\footnotetext{
${ }^{5}$ Recientes análisis exponen las características actuales del federalismo. Cf. Aguilar Villanueva, Luis F. (1995); Gadsden, Carlos et al. (1995); Martínez Assad, Carlos (1994).
} 
Ahora bien, en México, en los primeros años de la década de los años ochenta, la propuesta de "descentralización de la vida nacional" fue un componente central en la agenda del gobierno de Miguel de la Madrid (1983-1988). La misma dio lugar a un proceso de desconcentración de funciones y recursos del gobierno federal a los estados (y en menor medida a los municipios), sin que se lograra alcanzar un proceso auténticamente descentralizador. La contrapartida de esta desconcentración fueron las restricciones impuestas en la capital del país para la localización de nuevas actividades (sobre todo las que requerían consumir agua y/o contribuían a deteriorar el ambiente urbano). Sin duda, esta política incidió para que el capital privado agregará un motivo más a su decisión de localizarse, cada vez más, en otras ciudades del país.

Durante esa administración se formuló un amplio y vasto programa de desconcentración que abarcaba inicialmente todas las dimensiones de la actuación gubernamental (económica, política, de educación, salud y servicios públicos). Un impulso inicial del gobierno federal fue promover reformas al art. 115 constitucional, traspasando a estados y municipios un conjunto de responsabilidades en relación con el suministro de servicios públicos (agua potable y alcantarillado, recolección de basura), el mantenimiento y administración de bienes colectivos (espacios verdes, mercados), la planeación del territorio y la captación de recursos propios (impuesto predial y traslado de dominio). Los principales instrumentos con que contó la administración pública para llevar a efecto esta desconcentración de recursos fueron los Convenios Únicos de Desarrollo (CUD) que dentro del marco de los Comités de Planeación para el Desarrollo (Coplade), establecían el destino de los recursos, de acuerdo con prioridades fijadas localmente ( $c f$. Martínez Assad, Carlos y Alicia Ziccardi, 1992).

En materia de política urbano-regional, esta posición inicial del gobierno federal y el uso de los instrumentos ideados para desconcentrar y fortalecer la acción en el nivel estatal, se sustentaban en diagnósticos físico-espaciales elaborados por el personal de la entonces Secretaría de Asentamientos Urbanos y Obras Públicas (SAHOP), instancia del gobierno federal creada en 1976. La eficacia de esta práctica planificadora centralizada fue ampliamente criticada, principalmente porque dio origen a la proliferación de miles de planes y programas, muchos de los cuales carecían de rigor técnico y de la consideración de los actores gubernamentales (niveles de gobierno y/o tipo de organismos), económicos (empresariales, bancos) y sociales (organizaciones y/o movimientos sociales) que actuaban en los procesos de ocupación y uso del suelo. ${ }^{6}$ Pero, esta planeación urbano-regional partía de un diagnóstico global correcto en el que se señalaba que muchos problemas nacionales provenían de la existencia de un patrón de urbanización caracterizado por una marcada concentración de población y actividades en las grandes áreas metropolitanas (en particular la ciudad de México y en orden de importancia Guadalajara y Monterrey). Su contrapartida era la dispersión de población y acti-

\footnotetext{
${ }^{6}$ Un balance sobre la planificación urbano-regional de esos años puede hallarse en el libro colectivo coordinado por Gustavo Garza: Una década de planeación urbano-regional en México (1978-1988), El Colegio de México, México, 1989.
} 
vidades en miles de pequeñas localidades ( $c f$. Unikel, Luis, 1976). Las propuestas de la época consistieron en promover una desconcentración, a fin de que disminuyeran las desigualdades regionales $\mathrm{y}$, por esta vía, se contrarrestaran los efectos de la aguda crisis que presentaba la economía nacional.

Según se afirmaba en el Plan Nacional de Desarrollo de 1983, la ciudad de México (considerada en ese texto como la zona metropolitana constituida por el D.F. y los municipios conurbados del Estado de México) era un espacio altamente concentrador de los recursos nacionales, "más allá de lo que es económicamente eficiente en el contexto interregional". El principal efecto de esta primacía urbana, que por cierto iba perdiendo peso en la década de los ochenta, ${ }^{7}$ era el producir un proceso de desarrollo innecesariamente lento y costoso que se traducía en la creciente exigencia de realizar cuantiosas inversiones públicas para atender las necesidades básicas de la población de la zona. Por ello, la principal propuesta de la tecnocracia de la época era la reordenación de las actividades económicas en el territorio nacional, para lo cual debía desestimularse la inversión industrial en la ciudad de México, territorio que presentaba ya serias dificultades para garantizar el suministro del agua potable a vastos sectores de la población, así como elevados niveles de contaminación ambiental. En contrapartida, el discurso de la época retomaba nuevamente las viejas ideas de estimular el desarrollo regional y el desarrollo estatal integral y, agregaba, el fortalecimiento municipal.

Era evidente que la ciudad de México históricamente, y por razones de índole geográfica, económica y política, había concentrado fuertemente la inversión pública federal. Pero esta situación había comenzado a ceder en los ochenta ante los requerimientos de infraestructura exigidos por el auge de las actividades petroleras principalmente en el Golfo de México, el fomento al turismo y los proyectos vinculados a la creación de parques y puertos industriales. Por otra parte, la producción de insumos o productos intermedios comenzó a localizarse en el interior del país, en ciudades en las que existía ya una importante oferta de mano de obra y ofrecían otras ventajas locacionales (ej.: la maquila en las ciudades de la frontera norte). Todo ello llevó a que, en esta década, las llamadas ciudades medias o secundarias adquiriesen una creciente importancia en el mapa de la nación ( $c f$. Aguilar, Adrián y Boris Graizbord, 1992).

Durante el gobierno de Miguel de la Madrid, la SAHOP se convirtió en Secretaria de Desarrollo Urbano y Ecología (SEDUE), otorgándosele rango de subsecretaría al tema de la vivienda y al ambiente. Pero esta instancia gubernamental, que perdió entonces su anterior capacidad de ejecutar obras públicas, asumió un carácter exclusivamente normativo y careció de capacidad para influir en la formulación

\footnotetext{
${ }^{7}$ Investigaciones posteriores realizadas por el Consejo Nacional de Población (1994:29) indican que entre 1900 y 1950 se observó un aumento gradual de la primacía de la ciudad de México respecto de las otras tres principales ciudades: Guadalajara, Monterrey y Puebla; en las décadas siguientes se presentó una disminución; y entre 1970 y 1980 no existía variación significativa del índice de primacía, aunque se mantuvo una tendencia a la disminución respecto de las diez principales ciudades. Pero es en la década de 1980-1990 cuando se observa claramente que la zona metropolitana de la ciudad de México ha perdido peso frente a los otros centros urbanos más grandes del país, lo cual no significa que continúe creciendo su población.
} 
de políticas y acciones gubernamentales que tenían efectos territoriales. ${ }^{8}$ Fue la entonces existente Secretaría de Programación y Presupuesto la que diseñó la política de desarrollo regional y definió la asignación de la inversión pública federal. La ciudad de México continuó aportando importantes recursos a la federación y también recibiendo una alta proporción de los mismos para su administración y para la producción de obras públicas.

Los alcances de este proceso de desconcentración administrativa y territorial ya fueron estudiados (véanse, entre otros, Jacobs y Ziccardi (1984), Massolo, Alejandra, 1991; Moreno Toscano, 1984). Entre los principales obstáculos a los proyectos desconcentradores impulsados por el gobierno federal deben mencionarse las propias resistencias de los gobiernos estatales y del sindicalismo, que vio amenazado su poder sobre los recursos de los trabajadores. En lo fundamental, se trató de una desconcentración centralizada, programada y ejecutada por el ejecutivo federal, lo cual generó algunos beneficios, pero también altos costos económicos y sociales en los estados y municipios receptores de la misma.

Sin embargo, la forma de operar del sistema federal mexicano comenzaba a ser cuestionada. Más allá de la intención gubernamental de restructurar profundamente la economía, los partidos de oposición comenzaban a disputar y obtener puntuales pero importantes triunfos en gobiernos municipales; varias ciudades del norte del país pasaron a manos del PAN, por ejemplo Ciudad Juárez ( $c f$. Padilla, Héctor, 1995), mientras que la izquierda, lograba controlar un combativo gobierno local en Juchitán, Oaxaca ( $c f$. Zermeño, Sergio, 1987). Los triunfos de la oposición en el nivel municipal fueron la base de las exigencias que sistemáticamente comenzaron a colocar los estados ganados por la oposición, cuyos gobiernos locales pugnaban por una distribución más justa de los recursos de la nación, puesto que de ello dependía el lograr mayor autonomía respecto del gobierno central (cf. Martínez Assad, Carlos, 1983; Lujambio, Alonso, 1995).

Pero la disputa centro-provincias se funda en una histórica adversidad y su sobrevivencia señala la necesidad de restructurar un aparato estatal fuertemente controlado por el nivel federal y a la vez revisar las relaciones entre órdenes de gobierno. El gobierno de Miguel de la Madrid propició una desconcentración territorial de recursos, pero esto se hizo de manera centralizada; por ello no hubo descentralización (en el sentido en que fue definido en este trabajo) ni una profunda revisión de las relaciones intergubernamentales entre órdenes de gobierno.

Mientras tanto, la ciudad de México transformaba profundamente su economía y su estructura urbana. Hacia el final del sexenio se aprobó el Plan General de Desarrollo Urbano del D.F. (1987-1988), en el cual se planteaban algunas tesis básicas como: controlar y ordenar el crecimiento de la Zona Metropolitana de la Ciudad de México (ZMCM), formular políticas de descentralización y de desconcentración de industrias contaminantes, prohibir nuevos fraccionamientos, reconstituir la zona central de la ciudad de México, reordenar la ciudad en ocho sectores (centros, subcentros, corredores urbanos y zonas especiales de desarrollo conur-

\footnotetext{
${ }^{8}$ En particular nos referimos a las obras de infraestructura (caminos, carreteras) que se trasladaron a la Secretaría de Comunicaciones y Transportes (Cf. Ziccardi, Alicia, 1991).
} 
bado [ZEDEC]), conservar el ambiente y desarrollar instrumentos de planeación y normas jurídicas.

Pero en los hechos, la ciudad de México, continuó absorbiendo buena parte de la inversión pública federal para dar continuidad a sus monumentales y necesarias obras de infraestructura y equipamiento (en particular, el metro y el drenaje profundo). A ello se agregaron los efectos urbanos de los sismos de 1985, efectos contradictorios que pusieron nuevamente de manifiesto la difícil relación capital-nación. Así, por un lado, fue necesario que la nación (el gobierno federal) asumiese la atención de las justas demandas de vivienda de los damnificados, para lo cual se usaron recursos del presupuesto y se obtuvieron apoyos de organismos internacionales, los cuales fueron aplicados a la construcción de aproximadamente cien mil viviendas y a la reconstruccion de infraestructuras y equipamientos. Por otro, los sismos provocaron que un considerable número de familias optaran por trasladarse a vivir en el interior del país. Un efecto sociopolítico importante fue que con la tragedia y ante la capacidad de organización que demostraron los damnificados, se lograron modificar las tradicionales y autoritarias relaciones que prevalecían entre las instituciones gubernamentales y la ciudadanía y se dio origen a un proceso de reconstrucción con participación social. ${ }^{9}$

Hacia el final del sexenio en 1987 se creó la Asamblea de Representantes del D. F. (ARDF), primer paso para democratizar, por la vía de la elección directa de representantes políticos, la estructura de gobierno de la ciudad capital. Con ello se abría un canal de representación política de la ciudadanía. Aunque en su primera etapa sólo tuvo funciones reglamentarias, esta instancia se encargó de gestionar diferentes demandas ciudadanas; es decir, fue una válvula de escape ante la fuerte tensión social que se había generado en la capital del país y que se transformó luego en un importante caudal electoral para el movimiento de oposición que llevó a Cuauhtémoc Cárdenas a la candidatura para la presidencia en 1988 (cf. Bassols, Mario y Rocío Corona, 1992). Pero lo importante es registrar que a casi 60 años de la creación del Departamento del Distrito Federal (medida con la cual se suprimieron los municipios de la ciudad de México), se daba un primer paso para avanzar en la reforma política al gobierno de la ciudad capital. En adelante, el binomio descentralización-reforma política pasaba a ocupar un lugar central en el interior de la agenda política local y nacional.

\section{LA REFORMA DEL ESTADO Y LA REFORMA AL GOBIERNO DE LA CIUDAD DE MÉXICO}

Para la ciudad de México, la política de descentralización territorial marcó el inicio de un proceso de desindustrialización de la economía local, el cual se intensificó durante la administración de Carlos Salinas de Gortari (1989-1994), cuando se

\footnotetext{
${ }^{9}$ Existe una abundante bibliografía sobre los efectos urbanos, sociales y políticos que generaron los sismos de 1985 en la ciudad de México; entre otros pueden consultarse: Mecatl, José L., Marco Michel y Alicia Ziccardi (1987); Massolo, Alejandra (1886); Connolly, Priscilla, Emilio Duhau y René Coulomb (1991).
} 
adoptó un conjunto de políticas económicas neoliberales y se puso en marcha un proyecto de reforma del Estado, dando lugar a procesos de restructuración económica e institucional acordes con lo que ocurría en el contexto internacional.

Entre las principales decisiones que afectaron directamente los procesos de uso del territorio nacional deben mencionarse: la disminución del tamaño y funciones del gobierno central y el traspaso de responsabilidades a los gobiernos estatales y municipales, la desregulación de las formas de acceso y uso del suelo y demás componentes de la estructura urbana, y la privatización de servicios urbanos en algunos estados y municipios del país (ej.: el agua potable, la recolección de basura, etcétera). A ello se agregan los efectos propios del TLC (principalmente en las ciudades de la frontera norte) y las modificaciones al artículo 27 constitucional sobre la tenencia de la tierra. La descentralización, aunque no estaba ausente del discurso gubernamental, se reinscribió en el interior de las políticas de reforma del Estado. Como parte de las mismas, se trató de neutralizar el intermediarismo (particularmente sindical) y se restructuraron las políticas sociales de corte corporativo, que habían prevalecido durante varias décadas. Esta acción también tuvo importantes efectos sobre el gobierno y la administración urbana.

El discurso planificador, heredado del sexenio anterior, enunciaba objetivos de la descentralización, el desarrollo económico, el mejoramiento en la calidad de los servicios urbanos, el fortalecimiento municipal y el impulso a la planeación democrática para el desarrollo urbano y regional ( $c f$. Plan Nacional de Desarrollo 19891994). Pero lo cierto es que las políticas territoriales, urbano-regionales carecían de importancia en el interior del aparato gubernamental. En lugar de restructurarlas, ponderando el significado que encierra la dimensión territorial en los procesos de restructuración económica, se optó por su omisión. La instancia encargada de su tratamiento, la SEDUE, cambio su nombre por el de Secretaría de Desarrollo Social (Sedesol), pero ello no significó que esta secretaría dejase de lado la normatividad territorial para asumir el diseño y/o ejecución de las políticas sociales (salud, educación) o el control del Sistema de Ahorro para el Retiro (SAR, nuevo mecanismo de seguridad social y ahorro para la vivienda de los asalariados, creado en 1992). La Sedesol se transformó, en cambio, en el aparato institucional desde el cual se operaba el publicitado programa social de distribución de bienes y servicios destinado a contrarrestar los efectos del ajuste sobre los sectores pobres de la población: el Programa Nacional de Solidaridad (Pronasol). Este programa se enmarcaba en los lineamientos que formularon los diferentes gobiernos latinoamericanos, de acuerdo con las recomendaciones de los organismos prestatarios internacionales, en particular el Banco Mundial.

Durante el salinismo, el presidencialismo ejerció un fuerte control sobre la vida económica y política de los estados y municipios del país, y el Pronasol fue un mecanismo eficaz para ello, concentrando los recursos del ramo 26 del presupuesto federal. ${ }^{10}$ Sin embargo, la presión política de una oposición que creció en los es-

${ }^{10}$ Seguramente pocos programas gubernamentales han sido tan evaluados y estudiados como Pronasol, programa sobre el cual existe una abundante bibliografía; véanse entre otros: Dresser, De- 
tados del interior del país y obtuvo primero importantes triunfos en el nivel municipal y luego, en el estatal, generó los embriones de una exigencia de descentralización. Principalmente, en los estados en los que alcanzó el control del ejecutivo (Baja California, Guanajuato y Chihuahua, donde sus gobernadores habían sido ya presidentes municipales), el PAN comenzó a demandar una relación entre la federación y los estados más justa y más igualitaria en la distribución de los recursos y en el interior de las relaciones intergubernamentales. ${ }^{11}$

Si bien la dimensión territorial no fue explícitamente incorporada en la formulación de las políticas públicas, los movimientos del capital y la misma inversión pública federal (ej.: carreteras construidas y otorgadas en concesión al capital privado) contribuyeron presumiblemente al avance del proceso de desconcentración de actividades y población de la ZMCM hacia el resto de la región centro de otras ciudades del país.

En general, los efectos territoriales de las políticas públicas fueron poco o nada considerados en el interior de las mismas, el estallido de violencia en Chiapas es un indicador de ello. Los índices de marginalidad que dio a conocer el Conapo en 1993, en donde se advierten crudamente las desigualdades inter e intrarregionales, estatatales y municipales que prevalecen en el país en relación con los bienes y servicios básicos, no contribuyeron a diseñar nuevas políticas públicas capaces de contrarrestar el grave rezago social.

En materia de política urbana se formuló el Programa de las 100 Ciudades, según el cual se justificaba la organización y distribución territorial de la inversión pública federal, y los convenios con los estados cambiaron nuevamente su nombre para transformarse en Convenios de Desarrollo Social, instrumentos suscritos entre la federación y los estados de la república. En materia de política de vivienda, la situación fue desconcertante porque se optó por una actitud de desinterés y desconocimiento de la acción gubernamental desarrollada en el país durante los 20 años anteriores. Así, se regresó a la vieja y errónea idea de que el problema de la vivienda popular podía resolverse introduciendo mecanismos propios del mercado, se improvisaron nuevas y poco exitosas fórmulas de operación en los organismos de vivienda (como las subastas en Infonavit) o el desmantelamiento del único organismo para no asalariados, Fonhapo, que en su primera etapa había logrado ser una experiencia innovadora y con eficacia social. Sin duda, con esta política urbana se debilitaba el clientelismo sindical que, como una forma de distribución de bienes y servicios urbanos, prevaleció durante dos décadas para los asalariados; pero también se intentó debilitar las organizaciones sociales autónomas que habían aprendido a gestionar recursos para la vivienda y que, en adelante, debieron optar por disputar los limitados recursos de los organismos locales. Por ello puede afirmarse que, en general, la política urbana de nivel federal, lejos de fortalecer los gobiernos locales, los debilitó.

nis, 1994; Molinar, Juan y Jeffrey Weldom, 1994; Gordon, Sara, 1993; Arzaluz, Socorro, 1995; Padilla, Héctor, 1995.

${ }^{11}$ Véase Lujambio, Alonso, 1995; Aziz Nassif, Alberto, 1995. 
En la ciudad de México, los efectos no fueron diferentes. La política contenida en el Plan Nacional de Desarrollo (1989-1994) formulaba como principal objetivo el mejorar la calidad de vida de sus habitantes. Para ello se anunciaban propósitos precisos tales como: el control y ordenamiento de la ciudad, la disminución de los niveles de contaminación del aire, la regularización de la tenencia de la tierra, la creación de empleos, garantías de seguridad pública, restructuración del servicio de transporte, preservación del Centro Histórico. Esto implicaba a su vez tomar medidas drásticas, como prohibir estrictamente el establecimiento o ampliación de industrias altamente contaminantes o grandes consumidoras de agua, adoptar políticas de ahorro de energía, detener la expansión desordenada de la mancha urbana y la pérdida de reservas estrátegicas para el equilibrio ecológico. Para ello se requería, entre otras cosas, mejorar la relación financiera y fiscal de la capital con el resto del país.

Pero durante el sexenio no se actualizó el Plan General de Desarrrollo Urbano, tal vez porque el mismo se había aprobado en 1987, un año antes de comenzar el sexenio salinista, durante la gestión del regente Ramón Aguirre Velázquez. Sólo se expidió la Ley de Desarrollo Urbano del Distrito Federal, el 4 de enero de 1991, en la cual el Plan Director para el Desarrollo Urbano del D.F. estaba constituido por el conjunto de reglamentos, normas técnicas o disposiciones relativas para ordenar los destinos, usos y reservas del Distrito Federal y el mejor funcionamiento y organización de espacios urbanizados. Sin duda, la ley no podía reemplazar la existencia de un plan, pero quienes estaban al frente de la oficina de Coordinación de Reordenación Urbana y Protección Ecológica se mostraron abiertamente renuentes a elaborar instrumentos de planeación global y normativa para el D.F. y optaron por impulsar proyectos estratégicos. ${ }^{12}$

Los noventa significaron cambios profundos en la ciudad de México, ya que este territorio asumió un papel central en los intentos de integrar la economía nacional a la globalización. La capital presentó profundas transformaciones en su estructura económica y se agudizó un doble proceso ya en marcha: la desindustrialización y la terciarización de su economía; esto se tradujo en la expansión de los servicios del sector moderno (el capital financiero, las actividades de la informática, el comercio) y del sector informal (principalmente la fuerte presencia de los vendedores ambulantes en el centro de la ciudad). Sin embargo, la desigualdad social y la segregación urbana en la ZMCM (e inclusive en el interior del Distrito Federal) no disminuyó, y con ello la movilización ciudadana por bienes y servicios urbanos, en particular vivienda, ejerció una presión permanente sobre el gobierno de la ciudad.

La reducción del subsidio federal para el mantenimiento del aparato burocrático propició una reforma fiscal basada en la ampliación del número de contribuyentes y en la desregulación de la normatividad existente para usos del suelo, lo cual contribuyó a su vez a estimular la inversión privada. Según informaciones oficiales, el nivel de endeudamiento de la ciudad fue acorde a su capacidad de generar recursos propios, y las costosas obras públicas realizadas en el territorio de

${ }^{12}$ Cf. Garza, Gustavo, 1995; Ziccardi, Alicia, 1992. 
la capital fueron construidas con recursos propios (ej.: el metro se extendió hasta el Estado de México). Pero es claro que la metrópoli cambió su fisonomía también con cuantiosos recursos procedentes de otras instancias del gobierno federal, como es el caso de la Secretaría de Comunicaciones y Transportes (STC) para la realización de obras de infraestructura (puentes, vialidades, etcétera). Es precisamente en este punto donde la temática de la descentralización está directamente relacionada con la del federalismo.

Pero quizá lo más notorio fue que la gran ciudad vio transformar su espacio urbano a través de la realización de importantes megaproyectos, como fueron los centros comerciales en los que participó intensamente el capital privado y donde el gobierno local construyó la costosa infraestructura requerida (ej.: Santa Fe); este tipo de acción se enmarcó claramente en el papel de facilitador de las inversiones del capital privado que ha asumido el Estado y en la aplicación de las políticas neoliberales en la construcción del espacio urbano. También se impulsaron proyectos en los que participaron directamente los sectores populares, siendo el más importante el Proyecto de Rescate Ecológico de Xochimilco, y hubo otros que fracasaron a pesar de la centralidad que poseían, como fue el caso del Proyecto Alameda. Por otra parte, las reservas territoriales en el Ajusco pretendieron controlar la expansión de la mancha urbana, pero al mismo tiempo se desestimó la importancia de la planeación global de la ciudad y hubo que conciliar las exigencias de las clases altas y los intereses inmobiliarios sobre el uso del suelo (ej.: las ZEDEC y los ejes comerciales en Polanco o Altavista) con las exigencias de las clases populares (ej.: la demanda por servicios básicos en Iztapalapa).

En síntesis, la administración central privilegió los proyectos considerados estratégicos por la tecnocracia, tratando de conciliar los diferentes intereses que estaban en juego. Así, se realizó una intensa acción gubernamental vinculada, por un lado, con el capital privado y, por otro, con organizaciones sociales y organizaciones no gubernamentales (particularmente, de atención a la vivienda popular). La concertación fue una forma de relación que privó con las organizaciones ciudadanas en un contexto de creciente politización y de expansión de la oposición política.

En 1993, la reforma al gobierno de la ciudad de México pasó a ser un tema central en el debate nacional. La reforma ya era una demanda de los partidos políticos de la oposición que solicitaban la creación del estado 32 (estado de Anáhuac o del Valle de México) y el gobierno de la ciudad, el DDF, decidió encabezarla. Su propuesta de reforma al gobierno de la capital dio lugar a una consulta pública sobre diferentes temas, los cuales fueron analizados en innumerables ponencias presentadas en las cuatro mesas que se constituyeron para tal efecto: 1) forma de gobierno y derechos ciudadanos, 2) hacienda pública, aspectos financieros y económicos del D.F., 3) coordinación metropolitana, organización territorial y gestión de servicios, y 4) procuración y administración de justicia. Pero la riqueza y variedad de las ideas expuestas no logró plasmarse en una profunda reforma institucional y política. Sólo se introdujeron reformas en los artículos respectivos de la Constitución para transformar la forma de gobierno y se aprobó un Estatuto de Gobierno del D.F. el 14 de julio de 1994. Sin duda, los limitados alcances de 
esta reforma deben enmarcarse en el contexto que prevalecía en el país. Se trataba de una reforma política iniciada con posterioridad a la recuperación del PRI en 1991, que contemplaba la elección indirecta del regente para 1997, la elección directa de consejeros ciudadanos delegacionales, mayores atribuciones a la Asamblea de Representantes del D.F. (en particular el control de la cuenta pública del DDF) y la creación de un Consejo Metropolitano para atender cuestiones relativas al suministro de servicios de escala metropolitana (ambiente, agua y transporte público).

Pero el estatus de la capital en el interior del pacto federal continuó inalterado; sólo se trató de introducir mejores o más eficaces mecanismos para institucionalizar la participación ciudadana y se dio un limitado avance con la propuesta de elección indirecta del regente por parte de los millones de capitalinos que habitan este territorio. No se introdujeron las propuestas sobre las necesarias transformaciones institucionales que se requerían para mejorar la gestión urbana, tales como de traspaso de funciones y recursos del DDF a las delegaciones, con lo cual la ciudad continuaría gobernándose con un presupuesto fuertemente concentrado en el nivel central.

La ciudad de México era considerada territorial y administrativamente como el Distrito Federal y no como la realidad metropolitana que la constituye. ${ }^{13}$ Para los diferentes órdenes de gobierno que conviven en este territorio: el DDF, las delegaciones, la ARDF, las instancias de gobierno del Estado de México y las autoridades municipales no se propusieron transformaciones sustanciales en cuanto a sus funciones, sus formas de relación y de coordinación.

Pero la reforma fue un paso importante en el sentido de poner a debate, en el espacio local (particularmente en la ARDF) y en el órgano de representación de los estados de la federación (el Senado), la forma de gobierno de la capital del país. Los tiempos políticos del orden nacional no la beneficiaron, ya que el sexenio expiraba y en consecuencia la forma de gobierno de la capital se dirimió en medio del tenso escenario de la sucesión presidencial. El entonces regente de la ciudad, Manuel Camacho Solís, no ocultó sus aspiraciones a ser el candidato del PRI a la presidencia de la república y esto condicionó marcadamente los alcances de la misma; por lo menos, la sujetó a los condicionamientos del presidencialismo. Así, la reforma se concretó a introducir algunas modificaciones en la forma de gobierno, las cuales estaban lejos de garantizar una gestión urbana eficiente y una gobernabilidad democrática. La capital tampoco lograba redefinir su lugar en el interior de un sistema federal que, desde la creación de esa forma de gobierno, se benefició con una alta concentración de recursos de poder, económicos y políticos.

${ }^{13}$ Sobre la complejidad de la administración de los principales servicios urbanos de la zona metropolitana de la ciudad de México, véase Navarro, Bernardo y Alicia Ziccardi (coords.), 1995. 


\section{LA REFORMA INCONCLUSA Y EL NUEVO FEDERALISMO}

Desde hace casi diez años se anunció la intención de reformar el gobierno de la ciudad de México y se avanza lentamente en su concreción. Sin duda, la capital es un espacio de poder real y simbólico, donde la oposición partidiaria (PAN y PRD) tienen un importante caudal electoral y, por ende, grandes posibilidades de disputar el gobierno al PRI. Por ahora, sólo se han realizado las elecciones de consejeros ciudadanos, previstas en el Estatuto de Gobierno, donde prevaleció un alto abstencionismo y un abierto desinterés de la ciudadanía por participar en un proceso en el que se limitó la actuación de los partidos políticos al control del proceso electoral.

Lograr concretar el objetivo de la reforma política es de fundamental importancia para avanzar en la transición e inaugurar una forma de gobierno democrático en la capital de México, una de las ciudades más grandes del mundo. Pero el gobierno de la ciudad de México requiere también una profunda reforma institucional que permita otorgar mayor eficiencia y eficacia a la gestión del territorio y que garantice calidad de vida para el conjunto de la población que habita la gran metrópoli. Por ahora, sólo están en juego las propuestas democratizadoras, pero las mismas deben articularse necesariamente al debate actual sobre el federalismo. Por ello, la reforma ahora deberá ser más profunda y compleja.

En el discurso gubernamental actual existen muy pocas alusiones sobre cuál es el estatus de la capital en el interior de lo que se ha dado en llamar el "nuevo federalismo". Sin embargo, el tema de la capital es central para saber cuál es el alcance de las reformas que se proponen. Se reitera la necesidad de realizar una descentralización de funciones y de recursos de la capital del país hacia los demás estados y municipios, lo cual no puede limitarse a una redistribución de las participaciones federales (una reforma fiscal) ya que es necesario considerar la importancia y centralidad que posee la economía urbana de la capital para el conjunto de la economía nacional. Así, según el INEGI, el D.F. aporta actualmente alrededor de un $24.1 \%$ del PIB global, principalmente porque aquí se localizan aún las principales actividades de la industria manufacturera y de los servicios de la producción. De igual forma, absorbe una proporción similar de la inversión pública federal, a lo que se agregan las transferencias de recursos que se dan entre el gobierno federal y el DDF, los recursos extraordinarios que se obtienen a través de la deuda y que sirven para financiar obras en la ciudad, etcétera. Lo fundamental es señalar que mientras no exista transparencia en las cuentas de la nación, y de cada nivel de gobierno, perdurará la idea de que la capital se beneficia por encima de lo que le corresponde en el pacto federal.

Pero el federalismo es mucho más que un arreglo fiscal; es un sistema de gobierno según el cual el poder se distribuye funcional y territorialmente entre los estados que constituyen la nación. El problema de la forma de gobierno de la capital, en los países que han optado por el federalismo, va más allá de lo económi- 
co y se ha resuelto de muy diversas maneras. ${ }^{14}$ En Argentina, la capital federal es una gran ciudad gobernada por una municipalidad que, hasta 1995, estaba en manos de un intendente designado por el presidente de la república y que ahora es electo por la ciudadanía, al igual que los miembros del Consejo Deliberante. Es decir, la forma de gobierno de su capital hasta hace poco era similar a la de la capital mexicana. En Brasil, en cambio, la capital se trasladó a finales de los años cincuenta de la ciudad de Río de Janeiro hacia Brasilia, una nueva ciudad que es asiento del gobierno federal y cuya máxima autoridad, el gobernador, es electo por la ciudadanía.

En México, hoy coincide temporalmente la intención de reformar el gobierno de la ciudad (o más bien, de crear un gobierno donde sólo exista un aparato administrativo y una instancia legislativa) con los proyectos de restructurar la forma de funcionamiento del sistema federal. Las tareas son complejas y deberán contemplar, entre otras, las siguientes cuestiones: 1) Crear una forma de gobierno democrática, lo cual implica que los habitantes del D.F. elijan de manera directa a sus autoridades más inmediatas (regente y delegados); 2) realizar una reforma político-institucional que descentralice hacia las delegaciones recursos económicos, técnicos, humanos y políticos, y modernice el aparato administrativo, poniendo fin a la corrupción que está presente, de diferentes maneras, en las instancias de gestión del territorio y de los servicios urbanos; y 3) formular una propuesta de reforma al gobierno de la ciudad de México, desde y en el interior del federalismo, integrando la transformación del gobierno de la capital a las transformaciones del gobierno de la nación.

\section{BIBLIOGRAFÍA}

\section{Descentralización}

Aguilar, Adrián Guillermo y Boris Graizbord, 1992, "Las ciudades medias y la política urbano-regional. Experiencias recientes en México", Investigaciones Geográficas, Boletín del Instituto de Geografia, UNAM, número especial, México, pp. 145167.

Aguilar Barajas, Ismael, 1992, "Descentralización industrial y desarrollo regional en México, 1970-1980", Investigaciones Geográficas, Boletín del Instituto de Geografía, UNAM, número especial, México, pp.101-145.

Ahumada Pacheco, Jaime, 1995, "El gobierno y la administración pública local en escenarios de la descentralización", Federalismo y Desarrollo, año 8, núm. 47, enero-febrero, México, pp. 7-28.

\footnotetext{
${ }^{14}$ Sobre la ciudad capital en los federalismos latinoamericanos véase Carpizo, Jorge, 1973; Carmagnani, Marcelo, 1993.
} 
Borja, Jordi, 1984, "Descentralización: una cuestión de método", Revista Mexicana de Sociología, año XLVI, núm. 4, octubre-diciembre, pp. 5-34.

Borja, Jordi, Fernando Calderón, María Grossi y Susana Peñalva (comps.), 1989, Descentralización y democracia. Gobiernos locales en América Latina, CLACSO, SUR, CEUMT-Barcelona, Santiago de Chile.

Consejo Nacional de Población, 1994a, Evolución de las ciudades de México 19001990, México.

Consejo Nacional de Población, 1994b, La población de los municipios de México 1950-1990, México.

Coraggio, José Luis, 1989, "La propuesta de descentralización: en busca de un sentido popular", en Laurelli, Elsa y Alejandro Rofman (comps.), pp. 491-522.

Coraggio, José Luis, 1991, Las dos corrientes de la descentralización en América Latina, Cuadernos del CLAEM, Montevideo.

Cornelius, Wayne, Ann Craig y Jonathan Fox, 1994, Transforming State-society Relations in Mexico, Center for US-Mexican Studies, University of California, San Diego.

De Mattos, Carlos, 1989, "La descentralización. ¿Una nueva panacea para enfrentar el subdesarrollo regional?”, en Laurelli, Elsa y Alejandro Rofman (comps.), 1989, pp. 335-363.

Dresser, Denise, 1994, "Bringing the Poor Back in: National Solidarity as a Strategy of Regime Legitimation", en Cornelius Wayne et al., 1994, pp. 143-165.

Garza, Gustavo, 1989, Una década de planeación urbano-regional en México 1978-1988, El Colegio de México, México.

Gordon, Sara, 1993, "La política social y el Programa Nacional de Solidaridad", Revista Mexicana de Sociología, año LV, núm. 2, abril-junio, pp. 351-366.

INEGI, 1993, Ciudad de México (Área Metropolitana). Perfil sociodemográfico, XI Censo General de Población y Vivienda, 1990, México.

Jacobs, Michael y Alicia Ziccardi, 1984, "La política de reordenamiento territorial en México: desconcentración y crisis", Revista Interamericana de Planificación, vol. XVIII, núm. 71, septiembre, pp. 178-185.

Laurelli, Elsa y Alejandro Rofman (comps.), 1989, Descentralización del Estado. Requerimientos y políticas en la crisis, Fundación Friedrich Ebert y Ediciones CEUR, Buenos Aires.

Martínez Assad, Carlos y Alicia Ziccardi, 1992, "Propuestas de descentralización del Estado mexicano", en Bazdresch, Carlos et al., México, auge, crisis y ajuste, Fondo de Cultura Económica, México, pp. 414-443.

Molinar, Juan y Jeffrey Weldom, 1994, "Electoral Determinants and Consequences of National Solidarity" en Cornelius, Wayne, pp. 132-141. 
Moreno Toscano, Alejandra, 1982, "México, modelo a desarmar", en Varios autores, El desafio mexicano, Océano, México, pp. 165-173.

Perló, Manuel y Alicia Ziccardi, 1989, "Déconcentrer ou descentraliser, telle est la question", en Schteingart, Martha (comp.), Changement social et mutations urbaines en Amérique Latine, CNRS-ORSTOM, París, pp. 201-221.

Poder Ejecutivo Federal, 1983, Plan Nacional de Desarrollo (1983-1988), México.

Poder Ejecutivo Federal, 1989, Plan Nacional de Desarrollo (1989-1994), México.

Poder Ejecutivo Federal, 1995, Plan Nacional de Desarrollo (1995-2000), México.

Rondinelli, Devis, 1981, "Goverment Decentralization", Comparative Perspective, International Review of Administrative Sciencies, XLVII, núm. 2.

Rufián, Dolores y Eduardo Palma, 1993, La descentralización, problema contemporáneo en América Latina, CEPAL, Dirección de ỉrogramas y Políticas Sociales, Santiago de Chile.

Unikel, Luis, 1976, El desarrollo urbano de México. Diagnóstico e implicaciones futuras. El Colegio de México, México, 2ª edición.

Varios autores, 1995, ¿Descentralizar en América Latina?, Programa de Gestión Urbana, Banco Mundial, GTZ, UNCHS, PNUD, Quito, Ecuador.

Ziccardi, Alicia, 1990, "Reflexiones sobre la investigación urbana y el poder local", en Martínez Assad, Carlos (coord.), Balance y perspectivas de los estudios regionales en México, Centro de Investigaciones Interdisciplinarias en Humanidades-UNAM y Miguel Ángel Porrúa, México, pp. 369-396.

\section{Federalismo}

Aguilar Villanueva, Luis F., 1996, "El federalismo mexicano: funcionamiento y tareas pendientes", Revista Mexicana de Sociología, año LVIII, núm. 3 julio-septiembre, pp. 3-38.

Carmagnani, Marcello, 1993, Federalismos latinoamericanos México/Brasil/Argentina, El Colegio de México, Fondo de Cultura Económica, México.

Carpizo, Jorge, 1973, Federalismo en Latinoamérica, Instituto de Investigaciones Jurídicas, UNAM, México.

Gadsden Carrasco, Carlos et al., 1995, Memoria del Foro Nacional Hacia un auténtico federalismo, Guadalajara.

González Oropeza, Manuel, 1995, El federalismo, UnAM, México.

Hernández Chávez, Alicia, 1993a, La tradición republicana del buen gobierno, Fideicomiso de las Américas, FCE, COLMEX, México.

Hernández Chávez, Alicia, 1993b, "Federalismo y gobernabilidad en México", en Carmagnani, pp. 263-299. 
Lujambio, Alonso, 1995, Federalismo y Congreso en el cambio político de México, UNAM, México.

Martínez Assad, Carlos, 1994, "Diagnóstico del federalismo mexicano", en Varios autores, La autoridad municipal y su compromiso con la democracia, Centro Nacional de Desarrollo Municipal, Secretaria de Gobernación, México, pp. 143-173.

Ocaña, Lucila, 1996, "La recomposición del Pacto Federal", Revista Mexicana de Sociología, año LVIII, núm. 1, enero-marzo, pp. 43-55.

Ortega Lomelín, Roberto, 1988, El nuevo federalismo y la descentralización, Editorial Porrúa, México.

Periódico El Nacional, 1994, Semanario Político Política, nueva época, núm. 5,7 de noviembre, México.

Periódico El Nacional, 1995, Suplemento Nuevo Federalismo, 7 de mayo, México.

Sales Gutiérrez, Carlos, 1987, Federalismo y fortalecimiento municipal, Banobras, México.

Vázquez, Josefina Zoraida, 1993, "El federalismo mexicano, 1823-1847", en Carmagnani, 1993, pp. 15-50.

\section{Ciudad de México- Forma de gobierno}

Bassols, Mario y Rocío Corona, 1992, "Entre la sociedad y el gobierno: la ARDF", Ciudades, núm. 13, año 4, México, pp. 52-57.

Beristáin Iturbide, Javier, 1993, "Comparecencia ante la ARDF”, México, mimeo.

Connolly, Priscilla, Emilio Duhau y René Coulomb, 1991, Cambiar de casa pero no de barrio, CENVI, UAM-A, México.

Cruz Rodríguez, Ma. Soledad, 1994, Crecimiento urbano y procesos sociales en el D.F. (1920-1928), UAM-A, México.

Departamento del Distrito Federal, 1987, Programa General de Desarrollo Urbano del Distrito Federal (1987-1988).

Garza, Gustavo, 1995, "Normatividad urbanística en la ciudad de México", México (mimeo.).

González Oropeza, Manuel, 1995, El federalismo, unAM, México.

Massolo, Alejandra, 1986, "iQué el gobierno entienda, lo primero es la vivienda!", Revista Mexicana de Sociología, año XLVIII, núm. 2, abril-junio, pp. 195-238.

Mecatl, José L., Marco A. Michel y Alicia Ziccardi, 1987, Casa a los damnificados, Instituto de Investigaciones Sociales, UNAM, México.

Moreno Armella, Florita, 1993, "Representación vecinal y gestión urbana en el D.F.”, El Cotidiano, núm. 57, agosto-septiembre, UAM, México. 
Navarro, Bernardo y Alicia Ziccardi (coords.), 1995, Ciudad de México: retos y propuestas para la coordinación metropolitana, UAM-X y Programa de Estudios sobre la Ciudad-unAM, México.

Perló Cohen, Manuel, 1980, "De cómo perdió la ciudad de México su municipalidad sin obtener a cambio una democracia de manzana", Revista Siempre, núm. 954, 2 de julio, México.

Samaniego Breach, Ricardo (comp.), 1992, Ensayos sobre la economía de la ciudad de México, México.

Sánchez Mejorada, Cristina, 1993, "Las clases medias en la gestión y el gobierno de la ciudad", El Cotidiano, núm. 57, agosto-septiembre, México.

Ziccardi, Alicia, 1991, Las obras públicas de la ciudad de México, Instituto de Investigaciones Sociales, UNAM, México.

Ziccardi, Alicia, 1992, "Las grandes ciudades: política urbana y modernización", Gestión y estrategia, número especial, enero-septiembre, UAM-A-Presidencia $\mathrm{Mu}$ nicipal del Ayuntamiento de Cuautitlán Izcalli, Estado de México, pp. 81-95.

Ziccardi, Alicia, 1993, "1928, un año difícil para el país y para su capital", El Perfil de La Jornada, 18 de junio, México.

Ziccardi, Alicia, 1995, "Gobiernos locales: entre la globalización y la ciudadanía (reflexiones sobre las transformaciones recientes en el D.F.", en Calva, J. L. y Adrián Aguilar (coords.), Desarrollo regional y urbano. Tendencias y alternativas, tomo I, CIIH, Instituto de Geografía-UNAM, pp. 145-162.

Ward, Peter, 1991, México: una megaciudad. Producción y reproducción de un ambiente urbano, Ed. Porrúa, México.

\section{Municipios-Forma de gobierno}

Arzaluz, Socorro, 1995, "Del movimiento urbano al gobierno local: el caso de la gestión del Partido del Trabajo en el municipio de Durango", en Ziccardi, Alicia (coord.), 1995, pp. 199-236.

Aziz Nassif, Alberto, "La construcción de un gobierno estatal de oposición: ¿rompimiento temporal del régimen de partido de Estado?", ponencia presentada en el coloquio internacional Las regiones ante la globalización. Competitividad territorial y recomposición sociopolítica, El Colegio de México, ORSTOM y Centre National de la Recherche Scientifique de Francia.

Cabrero, Enrique, 1995, La nueva gestión municipal en México. Análisis, de experiencias innovadoras en gobiernos locales, CIDE y Miguel Ángel Porrúa, México.

Guillén, Tonatiuh, 1993, Baja California 1989-1992. Alternancia política y transición democrática, COLEF, CIIH, México.

Martínez Assad, Carlos, 1983, Municipios en conflicto, IISUNAM-GV, México. 
Massolo, Alejandra, 1991, "Descentralización y reforma municipal ¿fracaso anunciado y sorpresas inesperadas?", en Varios autores, Procesos rurales y urbanos en el México actual, UAM-Iztapalapa, México, pp. 13-62.

Merino, Mauricio, 1994, En busca de la democracia municipal. La participación ciudadana en el gobierno local mexicano, El Colegio de México, México.

Padilla, Héctor, 1995, "Administración pública y conflicto político en la experiencia de un gobierno panista", en Ziccardi, Alicia (coord.), 1995, pp. 129-166.

Zermeño, Sergio, 1987, Juchitán: límites de una experiencia democrática, Cuadernos de Investigación Social 15, Instituto de Investigaciones Sociales, UNAM, México.

Ziccardi, Alicia (coord.), 1995, La tarea de gobernar: gobiernos locales y demandas ciudadanas, Instituto de Investigaciones Sociales-UNAM, Miguel Ángel Porrúa, México. 